\title{
TBC pulmonar infantil
}

DR. SERGIO IBANEZ Q.*.

\section{1.-Definición:}

Es una enfermedad infecto contagiosa producida por el Micobacterium Tuberculosis o Bacilo de Koch y que ataca a la especie humana a cualquier edad, preferentemente al hombre joven, dando lesiones principalmente en el pulmón, pero también extrapulmonares.

\section{2.-Etiologia:}

Es producida en el hombre por el Micobacterium Tuberculosis. Excepcionalmente otras formas de Micobacterium de variedad bovina e incluso aviaria pueden atacar también al hombre. El Bacilo de Koch es un germen alcohol ácido resistente (propiedad dada por su componente lípido) caracterizándose por su gran resistencia al medio ambiente, pudiendo conservarse en él durante meses o años.

\section{3.--Etiopatogenia:}

Es nocesario distinguir fundamentalmente dos formas de enfermedad tuberculosa en el niño. La tuberculosis primaria o primoinfección, forma más frecuente, que comprende el proceso que ocurre con la primera llegada al organismo del Bacilo de Koch y aquellas formas activas que se desarrollan algún tiempo después de curada la primoinfección, que corresponde a la reactivación endógena.

3.1. TBC Primaria: En el niño, el Bacilo Koch puede penetrar de distintas maneras al organismo, pudiendo hacerlo a través de la piel, aprovechando heridas o erosiones, por vía digestiva, oídos, etc.,

\footnotetext{
- Jefe Servicio de Neumotisiologia. Hospital Calvo Mackenna. Unidad Docente de Pediatria, Universidad de Chile, Area Oriente.
}

pero es con mucho, la vía aérea la más frecuente y habitual puerta de entrada. En esta forma se localiza en el pulmón, de preferencia en los segmentos inferiores de los lóbulos superiores o segmentos superiores de los lóbulos inferiores $y$ en las vecindades de la pleura.

Allí, produce lo que se ha llamado el chancro primario que es una pequeña zona (de uno o pocos $\mathrm{cm}$.) de neumonía tuberculosa y que general. mente es única. Su centro puede caseificarse rápidamente. En esta fase se produce el pasaje de pequeñas cantidades de Bacilo de Koch a la vía sanguínea (diseminación precoz). Estos Bacilos habitualmente son bloqueados, permaneciendo en forma latente durante meses o años, pudiendo, en algunos casos, reactivarse posteriormente, prodnciendo las formas de tuberculosis pulmonares y extrapulmonares (renales, meningitis, óseas, etc.).

Los bacilos de Koch del foco pulmonar primario son transportados por los vasos linfáticos hacia los ganglios regionales, causando en ellos lesiones caseosas con aumento de volumen. Este conjunto es lo que se denomina complejo primario TBC y que da en Ia radiografía la imagen en palanqueta; está formada por el foco pulmonar inicial, uno o más ganglios linfáticos en la región biliar o paraliliar y a lo que se agrega, a veces, el camino linfática que los une.

Estas lesiones pueden ser más o menos manifiestas, según los casos, siendo a veces imposible visualizarlas, aún en la radiografía, por su pequeño tamaño o por su localización.

El curso más frecuente seguido por el complejo primario, es hacia la curación, produciéndose la encapsulacion, fibrosis, y a veces calcificación. Otras veces se produce la reabsorción del foco parenquimatoso sin dejar huellas. En un número reducido de casos este complejo primario puede tomar un curso progresivo y el Bacilo de 
Koch propagarse por continuidad produciendo neumonias más extensas que pueden excavarse (cavernas). También pueden comprometer un bronquio y producir diseminaciones broncógenas. De la misma manera, los ganglios caseosos pueden alterar por vía linfática un bronquio vecino y ocasionar diseminaciones de extensión y gravedad variables.

La diseminación hematógena generalizada o miliar se produce por vaciamiento de material caseoso a un vaso sanguíneo o linfático, provocando así una siembra de nódulos finos en todos los 6rganos, teniendo principal importancia la localización meníngea y en el pulmón mismo. También estas formas progresivas pueden afectar estructuras vecinas del pulmón como la pleura y pericardio.

Cuando un niño se ha infectado, dos cambios importantes se producen. Uno es que el organismo se vielve alérgico al $B$. de Koch, (tuberculina positiva) y el otro, es que su reacción frente a él se altera habiendo una mayor resistencia tisular y humoral frente a su infección, lo cual otorga al organismo una mayor defensa o inmunidad contra la tuberculosis.

3.2. $T B C$ de Reactivación Endógena: Es más propia del adulto y niño mayor. Se produce por la reactivación del $B$. de Koch. aùn después de permanecer estacionario por meses o años. Se lócaliza en los lóbulos inferiores.

Progresa por vecindad, caseosis y excavación. Los bacilos también pueden causar una tuberculosis del árbol bronquial mismo.

\section{4.-Importancia Médico-Social.}

En nuestro país como en otros países en vías de desarrollo, la TBC tiene gran importancia médica-social, tanto por las altas cifras de mortalidad que ella provoca, como por la mortalidad elevada que todavía mantiene.

La TBC está ligada básicamente a las malas condiciones socio-económicas de la familia, al hacinamiento y al bajo nivel cultural. Sin embargo, por ser una enfermedad infecto-contagiosa puede afectar a cualquier individuo.

También en el niño la TBC es causa de un ausentismo escolar importante. Tiene importancia en nuestro país, al porcentaje de población aborigen, la cual evidentemente tiene menores condiciones de defensa racial frente a la TBC.

Un índice del riesgo de enfermar de una población lo da la investigación de la prueba de tuberculina.

En nuestro país el indice de infección escolar promedio es de un $20 \%$ (1971). Este porcentaje debe estimarse alto.
En cuanto a la mortalidad, se ha mantenido fa tendencia decreciente iniciada en el último decenio; así de una tasa de 52,2 por 100.000 en 1961 ha bajado en 1972 a una tasa de 23,6 por 100.000. De estas cifras el porcentaje de fallecidos menores de 15 años se ha mantenido alrededor de un $1,7 \%$ estando su mayor porcentaje en los lactantes.

\section{5.- Cuadro Clínico y Formas Clínicas:}

La tubersulosis primaria, forma más frecuente en el niño, suele evolucionar hasta estados relativamente avanzados, sin ninguna sintomatología, y pasar inadvertida. Pero también puede presentarse como un cuadro infeccioso agudo, con fiebre alta y compromiso acentuado del estado general (granulia; TBC miliar). En todo caso, en todo cuadro infeccioso, debe pensarse en la TBC y descartar su diagnóstico. Sólo teniéndola presente podtá hacerse su diagnóstico oportuno y precoz.

La sintomatología habitual en un niño portador de un complejo primario consiste en anorexia, baja de peso o falta de progreso ponderal, en el lactante, febrículas, adinamia o bien sintomas inespecíficos que pueden corresponder a lesiones de otros órganos o tejidos (formas miliar. meníngea, ganglionar, óses, genitourinarias).

El cuadro clínico de la reactivación endógena puede tener el comienzo propio de las formas de TBC del adulto y así debutar con una hemoptisis, como TBC pleural con dolor toráxico o, también, como formas similares a la primoinfección, es decir prácticamente asintomáticas. Puede presentarse también de manera insidiosa, catarral, como un cuadro respiratorio agudo, con fiebre, malestar, tos húmeda y que suele confundirse con gripe, bronquitis o neumonia.

Las formas extrapulmonares presentan el cuadro clínico y sintomatología propia de su localización (meningitis, articular, genitourinaria).

Hay algunos signos clínicos que orientan preferentemente hacia el diagnóstico de TBC, tales como el eritema nodoso, la queratoconjuntivitis flictenular, las tuberculides y los tubérculos coroídeos.

Una vez hecho el diagnóstico de TBC pulmonar es importante la determinación clínica en en lo que respecta al tipo de lesión. En lo que respecta a la extensión de la lesión, en su proyección radiográfica se distinguen formas inaparentes, formas mínimas, moderadas y avanzadas. La tuberculosis inaparente o no demostrable es aquella en que se ha detectado un viraje tuberculínico. dentro de un plazo de un año como máximo, o bien, cuando se encuentra una tuberculina positiva en un niño no vacunado BCG siempre que sea menor de 4 años. En esta forma no es posible 
encontrar la lesión en la radiografía pulmonar por ser pequeña o por su ubicación.

Las formas minimas son aquellas TBC activas en que se encuentran una lesión poco extensa, no cavitaria, con escasa población bacilar, que puede consistir en adenopatías hiliares o parahiliares solas o acompañadas de la imagen del foco pulmonar, habitualmente pequeño: constituye el complejo primario típico. Estas lesiones son generalmente benignas.

Las formas moderadas constituyen lesiones TBC más extensas, pero no mayores de un tercio de un campo pulmonar. Pueden consistir en adenopatías hiliares proyectadas en ambos campos, atelectasias lobares o segmentarias; y cavernas pequeñas aisladas que no excedan de $4 \mathrm{~cm}$. de diámetro en el escolar, $3 \mathrm{~cm}$. en el preescolar y $1 \mathrm{~cm}$. en el lactante.

Formas avanzadas. Se considera como tal toda lesión densa que ocupa más de un tercio de un campo; lesiones diseminadas que ocupan una superficie más allá de un campo y cavernas mayores de $4 \mathrm{~cm}$. en el escolar.

Actividad. En lo que respecta a su actividad, ella puede determinarse atendiendo a los factores evolutivos, tanto radiológicos, como bacteriológicos.

Se considera activa una lesión cuando en una serie de radiografías, a intervalos no mayores de 6 meses, se encuentran cambios ya sea hacia la mejoría o aumento de lesiones. La presencia de cavidad casi siempre significa actividad, aun cuando el estudio bacteríológico no revela la existencia de B. de Koch, ya sea en espectoración, contenido gástrico o secreciones aspiradas de bronquios.

\section{6.- Examen físico y sintomatología.}

La sintomatología de la TBC en el niño es muy variable y generalmente poco relevante $e$ inespecífica.

En las formas habituales de TBC primaria en sus grados mínimos y aún moderados el examen pulmonar casi siempre es negativo. Suele acompañarse de sintomatología general como anorexia, baja de peso, decaimiento, febrículas y tos. Cuando se encuentran síntomas y signos claros de lesión pulmonar, se trata de formas avanzadas, complicadas y progresivas.

Los signos van a depender del tipo de lesión y de las estructuras comprometidas; así el compromiso parenquimatoso neumónico puede dar estertores húmedos, finos. La lesión bronquial con su consecuente atelectasia dará los signos propios de ella, como asimismo el compromiso pleural dará signos y síntomas correspondientes a un mayor o menor derrame. En general, podríamos decir que la TBC se caracteriza por una pobreza en la signología pulmonar y un mayor hallazgo radiológico, en comparación con un cuadro pulmonar agudo.

En cuanto a la TBC pleural ella puede asociarse a una TBC primaria; casi siempre es unilateral. Su incidencia ocurre a edades superiores en el niño, párvulo y escolar más frecuentemente. Es decir, cuando ya hay un estado de alergia establecido. La lesión puede consistir en una pleuritis sin derrame o con derrame serofibrinoso, de cuantia variable, el que a veces puede llegar a producir comprensión del mediastino. Su signología puede ser nula o muy escasa si no va acompañada de derrame importante o puede ella dar todos los signos y síntomas que acompañan a cualquier derrame: dolor toráxico, fiebre, macidez y disminución o abolición del murmullo vesicular. En las TBC extrapulmonares el examen físico y la sintomatología van a estar dictadas por el órgano o sistema comprometido (meninges, articulaciones, aparato genitourinario, etc.).

\section{7.-Exúmenes de Laboratorio:}

El diagnóstico de certeza de la TBC pulmonar sólo se establece con la demostración del Bacilo de Koch. Sin embargo, en el niño, por el hecho de tratarse en la mayoría de los casos de lesiones cetradas o poco bacilíferos el porcentaje de hallazgo del Bacilo de Koch es bajo, comparado con el adulto. A pesar de ello es un examen que debe hacerse siempre ya que sirve, además de asegurar el diagnóstico, para seguir la evolución de la enfermedad y para observar la eficacia del tratamiento.

Es por ello que el estudio de la Tubercutina y el examen radiológico son indispensables para diagnosticar la TBC en el niño.

Otros exámenes tienen una importancia secundaria como el hemograma y la sedimentación, que son inespecíficos.

En determinadas formas de TBC, la Biopsia, el líquido cefalorraquídeo, líquido pleural $\mathrm{y}$ fondo de ojo prestan ayuda decisiva.

La búsqueda del Bacilo de Koch en el niño se hace habitualmente en el contenido gástrico, ya que el lactante y niño pequeño no espectora y deglute sus secreciones. Si hay espectoración, en niños mayores, debe buscarse en ella. En el contenido gástrico la positividad es de un 20 a $30 \%$ $y$ en la espectoración de un 70 a $80 \%$.

E1 estudio de la resistencia del Bacilo de Koch a las distintas drogas anti TBC, se hace funda- 
mentalmente para conocer la prevalencia de la resistencia primaria y secundaria de una población lo cual es una manera evidente de conocer la efectividad del tratamiento quimioterápico antituberculoso.

Su importancia en el caso individual es limitada porque al contar con tratamientos normalizados de segunda línea y de excepción se puede pasar a ella basados sólo en la evolución clínica bacteriológica (persistencia o reaparición del Koch en presencia de un tratamiento bien llevado 0 evidente progtesión lesional).

La prueba de taberculina o PPD debe bacerse siempre en todo niño en que se sospeche una TBC. Su valor es limitado en el caso individual, por cuanto su positividad no siempre significa enfermedad, ya que puede estar infectado (no activo) o vacunado $B C G$.

La medición de la infección tuberculosa como índice epideniológico adquiere cada día mayor importancia. La prevalencia de individuos infectados de una población no vacunada traduce fielmente la situación epidemiológica en relación con la TBC en esa población y la incidencia de infección anual traduce el riesgo y, por lo tanto, la transmisión de la enfermedad.

Normas para su aplicación y uso. Se debe usar la Prueba Tuberculínica Standard International. Siempre deberá anotarse la presencia o ausencia de cicatriz de BCG. Se debe usar el PPD Rt. 23, adicionado de Tween 80 diluído por el Instituto Bacteriológico en concentración de 2 UT $(0,004$ mg.) por $0,10 \mathrm{cc}$. Esta preparación debe conservarse en refrigerador y protegida de la luz desde su entrega por el Instituto Bacteriológico. Nunca debe usarse la tuberculina después de la fecha de vencimiento. Deben utilizarse jeringas que no filtren, preferentemente del tipo Omega, provistas de émbolo con anillo de goma. En cuanto a las agujas deben usarse intradérmicas adaptables a la jeringa. Para estudios en grandes grupos se recomienda la aguja de platino que pueda flamearse. Las jeringas $y$ las agujas deben usarse exclusivamente para PPD.

Técnica. Se utiliza Ia intradermorreacción de Mantoux, inyectando $0,10 \mathrm{cc}$. de PPD 2 en la cara externa del antebrazo izquierdo, en la unión del tercio superior con el tercio medio. Cada vez que tenga que repetirse el test por cualquiera causa (defecto de técnica uso de concentraciones mayores) se debe cambiar el sitio de la inyección haciéndolo sucesivamente en el punto simétrico del antebrazo derecho, tercio inferior de la cara anterior del antebrazo izquierdo y tercio inferior de la cara anterior del antebrazo derecho.

Lectura. La reacción debe leerse a las 72 horas (3 días), midiendo con regla transparentc graduada en mm. el diámetro transverso máximo de la induración palpable aunque otros diámetros sean mayores. Sólo se tomará en cuenta la induración y no el eritema o edema. Se anota la presencia de vesículas, si las hay.

Se considera positiva toda reacción con jnduración de $6 \mathrm{~mm}$. o más, en su diámetro transverso. Dejar constancia si existe o no cicatriz de BCG.

Examen radiológico. La radioscopía sólo revela lesiones relativamente groseras y sirve más bien como un examen previo de sospecha de la existencia de una TBC, ya que lesiones pequeñas o finas pueden escaparse.

El Abreu y la placa radiográfica constituyen el medio más fidedigno para descubrir y seguir la evolución de las lesiones TBC., en el niño. Sin embargo, muchas veces no establecen un diagnóstico etiológico, por lo que debe siempre asociarse a los otros exámenes y antecedentes para precisarlo. Lesiones muy pequeñas o de ubicación superpuesta con otras estructuras, no son visibles a la radiografía, como ocurre en la TBC primaria inaparente, no demostrable.

Es conveniente en el niño obtener radiografías en posiciones frontal y lateral, justamente para pesquisar en los hilios o zonas vecinales, que se escapan en la proyección frontal sola, y para precisar mejor la ubicación de la lesión parenquimatosa.

En el niño la imagen radiológica más corriente, consiste en la presencia del o los ganglios mediastinales comprometidos, de tamaño variable, junto con el foco pulmonar, lo que caracteriza el complejo primario y que constituye el hallazgo que nos permite sospechar con bastante certeza la existencia de una TBC primaria. Otras imágenes radiológicas, como atelectasia, neumonia caseosa o bronconeumonia tuberculosa, diseminaciones, etc., aún cuando suelen ser más o menos típicas de la tuberculosis, pueden ser dadas en forma semejantes por otras lesiones pulmonares no tuberculosas, debiendo hacerse siempre el diagnóstico diferencial. En nuestro medio la persistencia radiológica la hace sospechosa de TBC. También el hallazgo de ganglios en mediastino puede corresponder a otra patología como Hodgkins, Leucemia, tumores 0 adenitis virales e inespecíficas. Es frecuente también encontrar en la TBC pulmonar infantil calcificaciones que pueden corresponder a antiguos complejos primarios curados por calcificación o asociados a nuevas lesiones activas. Generalmente estas calcificaciones tienen gran densidad radiológica y son irregulares. Las cavernas, puede semejar un absceso pulmonar.

Exámenes especiales como broncoscopía, broncografía, planigrafía, punción pulmonar y estudio funcional respiratorio tienen su aplicación en ciertos casos especiales de investigación. 


\section{8.-Diagnóstico diferencial:}

Cada enfermo constituye un problema que debe ser resuelto convenientemente, para llegar al diagnóstico de Tubetculosis activa, antes de iniciar cualquier tratamiento.

Los elementos diagnósticos descritos, pueden usarse todos, siendo los más importantes el antecedente, el contacto el hallazgo de Bacilo de Koch, las pruebas tuberculínicas, los síntomas, la presencia de imágenes radiológicas y la biopsia.

Las entidades clínicas que necesitan mayor diferenciación son:

- Neumonías y Neumonitis.

- Bronquitis crónica, bronquiectasia, coqueluche.

- Adenopatía mediastínica: con neumonitis a virus (adenovirus), Linfomas, Hodgkin, Sarcoidosis, Leucemia, etc.

- Derrames pleurales.

- Abcesos pulmonares

- Mal formaciones y quistes

- Fibrosis

- Micosis, Histoplasmosis.

\section{9.-.- Control y Prevención}

Las medidas básicas de mayor rendimiento para bajar la curva de morbimortalidad son:

9.1. Prevención: La medida más útil es la vacunación.

En casos calificados también es de utilidad la Quimioprofilaxis.

9.2. Pesquisa, diagnóstico y tratamiento de los casos encontrados.

9.1. Normas de Vacunación: La vacunación BCG es una medida de alta prioridad en el programa actual de control de la tuberculosis. Se aplicará en recién nacidos y escolares de manera de obtener una máxima cobertura en estos grupos.

9.1.1. Primera vacunación (primovacunación). Se hará en las maternidades a los recién nacidos que pesan $2.000 \mathrm{gr}$. o más, simultáneamente con la vacuna Sabin monovalente tipo 1 . La excepción a esta norma la determinará el Médico Pediatra, recomenđándose la vacunación al alta.

9.1.2. Presentación de la vacuna. A) Vacuna liquida: es preparada por Instituto Bacteriológico y envasada en ampollas de $1 \mathrm{ml}$. (1 mg. de BCG. por ampolla). B) vacuna liofilizada: Contiene 1020,50 ó 100 dosis de vacuna desecada, para su dilusión en S. Fisiológico. Todas tienen 10 dosis por ml.

9.1.3. Conservación de la vacuna. a) vacuna líquida: debe conservarse en refrigeración a $4{ }^{\circ} \mathrm{C}$. Una vez sacada para su uso, debe ser protegida de la luz y del sol. b) vacuna liofilizada: debe conservarse en refrigeración a $4^{\circ} \mathrm{C}$. y debe, también protegerse de la luz.

9.1.4. Advertencia. No deberá utilizarse nunca la vacuna líquida vencida, debiendo destruirse las ampollas sobrantes en el momento en que liegue la nueva remesa, aunque no haya expirado la fecha de vencimiento. Abierta la ampolla y después de usar la dosis a emplear en ese momento, deberá eliminarse el sobrante. Nunca guardar una ampolla abierta. La vacuna liofilizada debe usarse inmediatamente después de preparada, siendo su duración máxima de 6 a 8 hrs. desde el momento de la preparación.

En las maternidades se utilizará la vacuna líquida. reservándose la liofilizada para la vacunación de escolares.

Preservación de la vacuna durante el transporte. Es de responsabilidad local preocuparse del inmediato retiro de la vacuna líquida del terminal del medio de transporte, para evitar el deterioro que se produce por la falta de refrigeración.

9.1.5. Instrumental y esterilización. Para practicar el B. C. G. es necesario emplear un equipo especial de jeringas y agujas, el que debe estar permanentemente separado de los equipos que se emplean on la aplicación de otros productos biológicos, especialmente de los usados para la prueba de tuberculina.

Para medir con precisión la cantidad indicada se usarán solamente las jeringas de tuberculina de $1 \mathrm{ml}$. graduadas en milímetros, que el Servicio entregue para este objeto.

Las elevadas presiones que exigen las inyecciones intradérmicas producen con frecuencia filtraciones en la jeringa entre el pistón y el cuerpo. $\mathrm{Si}$ esta filtración es importante, es imposible medir con precisión el volumen de B.C.G. inyectado. Por esto, deberá verificarse permanentemente si se produce esa falla y en ese caso descartarse la jeringa.

Existe actualmente una jeringa (Omega) cuyo pistón está provisto de una arandela de goma colocada en una ranura cerca de su extremo inferior, que impide la filtración. Con esta jeringa se emplean agujas de platino $(26 \times 6 / 8)$ o de acero (10 x 4/10 art. F2 de la Central de Abastecimiento del Servicio Nacional de Salud).

Estas jeringas y las agujas de platino se deben esterilizar al calor húmedo, por lo menos una vcz 
al día. Se puede emplear en la misma sesión de trabajo para muchas veces la aguja de platino, flameando al rojo la punta entre cada inoculación y dejando salir una gota de vacuna para enfriar la aguja antes de aplicarla.

9.1.6. Técnica de la inyeccion: Se monta la jeringa con la numeración y el bisel hacia arriba, de modo de visualizar la cantidad inyectada.

- Se agita enérgicamente la ampolla, antes de abrirla, hasta obtener una solución homogénea.

- Al usar vacuna liofilizada, se introduce el total del diluyente a la ampolla como paso previo a los dos anteriores.

- Cuando Ia jeringa se usa por primera vez en el día debe cargarse con $0,5 \mathrm{ml}$. de vacuna y mover el émbolo hasta que toda la pared interna de la jeringa quede húmeda; luego se devuelve el contenido a la ampolla y se carga la jeringa.

- Se introduce la punta de la aguja en las capas superficiales de la piel, (intradérmicas) cstirándola levemente a $2 \mathrm{~cm}$. debajo de vértice del hombro izquierdo, en la cara externa del brazo en el recién nacido y a $4 \mathrm{~cm}$. en el escolar. Hay que evitar doblar la aguja al introducirla en la piel, para impedir que se suelte en su base.

- Con lentitud se inyectará exactamente $0,1 \mathrm{ml}$. de $B C G$. Una cantidad menor no garantiza la efectividad de la vacuna y cantidades mayores determinan complicaciones.

En ningín caso deberá guiarse por el tamaño de la pápula al inyectar la vacuna.

- Debe tenerse siempre Ia precaución de agitar la jeringa antes de vacunar el niño siguiente, ya que la solución se decanta rápidamente, variando así enormemente la concentración de bacilos en la superficic respecto del fondo.

9.1.7. Evolución de la tesión vaccinal. En las primeras 48 horas puede producirse en el sitio de la inyección una reacción local de algunos milímetros de diámetro (mácula o pápula con punteado amarillento), esta inflamación pasa rápidamente.

Entre la tercera y la cuarta semana se forma un nódulo del tamaño de una lenteja o un poco mayor, que a menudo se resblandece en el centro y suele dar salida, por algunos días o semanas, a una pequeña cantidad de pus. En este caso la úlcera, así producida, cura en número variable de días, dejando una cicatriz.

Si la inyección no ha sido estrictamente intradérmica, sino que parte de ella ha Ilegado al tejido subcutáneo, puede formarse un nódulo mayor que el descrito anteriormente, el cual puede 1legar a adquirir las características de un abceso. En todo caso basta con mantener aséptica el área que rodea el sitio de la inyección.

La vacunación BCG produce habitualmente adenitis axilar de no más de $1 \mathrm{~cm}$. de diámetro y que no tiene mayor significación. Si se vacuna una persona alérgica, antes de diez días, se forma en la zona de inoculación un nódulo, incluso con reblandecimiento y supuración (fenómeno de Koch o reacción acelerada).

9.1.8. Complicaciones: Son fundamentamente dos:

- Adenitis axílar izquierda, supraclavicular e infraclavicular izquierdo, de mayor tamaño que el descrito. Estos infartos ganglionares si son mayores de $1 \mathrm{~cm}$. eventualmente pueden llegar a la supuración. Se presentan a partir de 2 meses después de la vacunación.

- Abceso local.

9.1.9. Lectura de la cicatriz. La lectura de la cicatriz BCG nos permite conocer si una persona ha recibido vacunación previa.

Li vacunación BCG deja una cicatriz caractcrística en el $95 \%$ de los vacunados, cuando se ha utilizado una buena técnica. Es una cicatriz pequeña, blanquecina, superficial y generalmentc deprimida. La dificultad más frecuente para la lectura es diferenciarla de la cicatriz dejada por la vacuna antivariólica, a la cual se asemeja. Al respecto, Jo más importante en la ubicación cuando se encuentra la región deltoidea izquierda próxima al vértice del hombro, corresponde a una cicatriz por $\mathrm{BCG}$.

La no existencia de cicatriz BCG nos permite afirmar que el individuo no fue vacunado, o fue con una vacuna poco potente o con una mala técnica.

La presencia n no de cicatriz debe ser verificada en cada caso.

9.2. Normas de pesquisa: La pesquisa de los casos de tuberculosis infantil se hará utilizando Ja reacción de Tuberculina. En Pediatría tiene la obligación de investigar la presencia de TBC en la familia, para ello debe determinar la existencia de sintomáticos tosedores y ordenar se practique el correspondiente examen de pesquisa baciloscorpica.

9.2.1. Tuberculina: Continúa siendo el procedimiento más útil, si se emplea una buena técnica. Debetá realizarse en los grupos más vulnerables y que dan mayor rendimiento, éstas son las siguientes: 
- Contacto de pacientes con tuberculosis pulmonar bacilifera; es el grupo de mayor rendimiento. En nuestro medio el caso índice está en el Hogar en un 93\%, con padres y abuelos en un $60 \%$.

Procedimiento: So efectúa la reacción con PPD 2 U. a todos los contactos menores de 14 aũos. Si la reacción es positiva debe completarse el diagnóstico.

$\mathrm{Si}$ la reacción de Tuberculina es negativa y el niño es menor de 2 años, se hará Quimioprofilaxis. Si el niño es mayor de 2 años, colocarle e] BCG.

- Sintomáticos respiratorios o de otras localizaciones extrapulmonares sospechosas (adenitis, SNC, osteoarticular, eritema nodoso, qucratoconjuntivitis flictenular, etc), que presenten tuberculina positiva, deben completar su estudio.

9.3. Normas de diagnóstico: En todos Jos casos sospechosos de tuberculosis pulmonar el diagnóstico se hará utilizando la radiologia y la bacteriología. En los casos de TBC extrapulmonar también debcrá hacerse un estudio histopatológico.

La radiología, por lo tanto, no deberá utilizarse como método de pesquisa en escolares, colonias veraniegas, jardines infantiles $\mathfrak{u}$ otros gcupos.

9.4. Quimioprolaxis: Medida de poca utilidad epidemiológica, en pediatría es una buena acción preventiva en casos calificados y siempre que se cuente con una organización operacional eficaz.

9.4.1. Quimioprotilaxis Primaria es aquella que se hace a los niños tuberculinos negativos expuestos a contagio. Se usa la Isoniazida hasta que cl foco dejc de ser bacilífero, y luego se coloca BCG.

Si se coloca BCG de partida, esperar 15 a 20 días para iniciar la quimioterapia con HIN (Los bacilos BCG son sensibles al HIN).

9.4.2. Quimioprofilaxis Secundaria: es aquélla que se efectúa en niños tuberculinos positivos, que están sometidos a riesgos espcciales: Diabetes juvenil, curas prolongada con Corticoides, lactantes, secuelas de tuberculosis no tratadas o mal tratadas en niños que estén bajo los 4 años de edad o en la pubertad. Se usa HIN mientras dure el riesgo.

9.4.3. Conducta a seguir frente al hijo de Madre Tuberculosa en el parto.

- Si se separa en el parto se coloca BCG y se entrega a la madre al mes, con Quimioprofilaxis.

- Si no es posible separarlo, no se coloca BCG y se entrega con HIN hasta que la madre deje de ser bacilífera; luego se coloca BCG.

\section{Tratamiento:}

El tratamiento de la tuberculosis en todas sus formas se centra en la Quimioterapia. Al curar el caso individual y esterilizarse la espectoración, se interrumpe la cadena de transmisión bacilar y desaparece el contagio, desarrollándose una acción epidemiológica efectiva.

Para que la quimioterapia sea eficaz debe hacerse una buena asociación de drogas, a dosis suficiente. Su administración debe ser controlada y por un tiempo prolongado.

Buena asociación signitica la administración de dos o más medicamentos a los que el Bacilo de Koch sea probablemente sensible y que al mismo tiempo eviten la proliferación de cepas resistentes.

Administración controlada significa que el enfermo recibe todos los medicamentos simultánermente, en una sola dosis, bajo la supervisión del personal previamente entrenado.

La duración del tratamiento es de 12 meses.

Sólo cumpliendo con estos requisitos las probabilidades de recaídas pulmonares o extrapulmonares son excepcionales.

La quimioterapia en su periodo inicial se administrará diariamente, en una sola dosis, durante un período que va de 4 a 6 semanas, con lo cual se logra producir una disminución brusca o importante. de la población bacilar. Después se continúa con un esquema simplificado diario o intermitente, 2 veces por semana, dando todas las drogas simultáneamente.

\section{Esquema de tratamiento.}

Son distintos en las diferentes formas de tuberculosis primaria que a continuación se enumeran:

\subsection{T. B. C. inaparente.}

10.2. T. B. C. demostrable, que incluye a la forma benigna, la progresiva, la pleuresía y la extrapulmonar de cualquier localización y extensión, excepto meningitis.

\subsection{Meningitis $T B C$.}

\subsection{Tuberculosis inaparente o no demostrable.}

A este grupo pertenecen los niños tuberculino positivos, menores de 4 años no vacunados $\mathrm{BCG}$ y los virajes tuberculínicos a cualquier edad, en un plazo inferior a un año desde el control anterior. Desde luego todos los niños de este grupo ticnen radiología negativa.

En el mayor de 4 años se usa Isoniazida (10 
mgr. por kgr. de peso) diario durante 12 meses. En el menor de 4 años se usan 2 drogas por 6 meses; pudiendo ser: HIN y PAS, SM y HIN, en este último esquema se usarán diarios 4 semanas para seguir con SM y HIN intermitente. Después de los 6 meses se continúa con HIN diario hasta el año.

\subsection{Tuberculosis demostrable.}

Estreptomicina (20 a $30 \mathrm{migr}$. por $\mathrm{kg}$. de peso) diario, en una dosis intramuscular, sin sobrepasar $750 \mathrm{mgr}$. Isoniazida (10 mgr. por $\mathrm{kg}$.) diario y PAS (200 a $250 \mathrm{mgr}$. por $\mathrm{kg}$. de peso) diario.

A las 4 a 6 semanas de tratamiento triasociado diario debe continuat con Isoniazida y PAS, diario, en ìguales dosis: o con Estreptomicina (igual dosis) más Isoniazida (15 mgr. por $\mathrm{kg}$. de peso) dos veces por semana, hasta completar 12 meses. El control del tratamiento debe efectuarse en base a la clínica, bacteriología y radiología.

En los niños con verificación bacteriológica se controlan a 3 meses en espectoración o contenido gástríco con el objeto de demostrar la positividad o negatividad del Koch. El estudio radiológico se efectúa al iniciar el tratamiento, a los 364 meses después y al término ( 1 año).

Criterio de fracaso: ante la persistencia bacteriológica o aparición reiterada en el curso de un tratamiento bien llevado o ante la evidencia de progresión lesional debe plantearse la modificación de los esquemas. Es recomendable referirlos a los centros especializados.

\subsection{Meningitis $T B C$.}

Usar 4 drogas, sin incluir PAS o Cicloserina, por su poca difusión en el líquido céfalo raquídeo.

Esquema de tratomiento: Estreptomicina e Isoniazida a iguales dosis señaladas anteriormente. Ethionamida (Trecator) $20 \mathrm{mgr}$. por $\mathrm{kg}$. de peso diario en una dosis, durante 2 meses. Continuar con Estreptomicina e Isoniazida intermitente dos veces por semana, hasta completar un año.

Los corticoides se usan de 1 a 2 mgr. por $\mathrm{kg}$. de peso diario de prednisona, por 45 días, en dosis decrecientes.

Los enfermos de Meningitis TBC deben ser derivados de jnmediato ( centros especializados, de acuerdo con la regionalización del SNS.

\subsection{Tratamiento quirúrgico:}

De gran utilidad en las adenitis a condición que sea completa extrayendo todo el paquete ganglionar.
En las tuberculosis pulmonares crónicas, resistentes, destructivas y localizadas, que plantean problemas por su poca cooperación la exéresis del foco principal es una buena ayuda a la quimioterapi:t.

\subsection{Corticoides:}

Por su acción antiinflamatoria, inespećffica, se emplean asociados a la terapia específica en los siguientes cuadros: Meningitis, Diseminaciones hematógenas (Miliar), Diseminaciones broncógenas importantes; Pericarditis, Pcritonitis y Atelectasias.

Su uso es optativo en la Pleuresia, Adenitis y TBC osteroarticular.

Dosis oral: Prednisona 1 a $2 \mathrm{mgr}$. por $\mathrm{kg}$. de peso, diario, en una sola toma, por 20 a 45 dias, en dosis decrecientes.

\subsection{Reposo:}

Conserva su indicación en las primeras semanas, durante el período evolutivo y sólo en las formas activas; pasado este periodo (2 meses) puede volver al colegio, reintegrándose gradualmente a la vida normal. En la forma inaparente no hay indicación de reposo.

\subsection{Hospitalización:}

En las formas avanzadas, diseminadas y extrapulmonares la hospitalización es recomendable para poder efectuar su diagnóstico deferencial, tomar las muestras bacteriológicas e histológicas e iniciar oportunamente su correcto tratamiento. Las formas moderadas o mínimas no requieren hospitalización.

La hospitalización no debe prolongarse, a excepción de ia Meningitis.

\section{Drogas antituberculosas. Izoniazida (HIN).}

Es la más efectiva, la más barata y la menos tóxica. Muy soluble, se absorbe rápidamente distribuyéndose en todos los tejidos y líquidos orgánicos, incluyendo el L. C. R. Se elimina por la orina, después que gran parte ha sido inactivada por acetilación a nivel hepático. Dosis: $10 \mathrm{mgr}$. por $\mathrm{kg}$. de peso al día, en una sola toma ora!.

Cuando se usa formando parte de un esquema intermitente bisemanal, es necesario subir la dosis $15 \mathrm{mgr}$. por $\mathrm{kg}$. en una sola dosis y lo más cerca posible de la inyección de SM.

Los niveles séricos alcanzados son 30 a 50 veces superiores a las dosis mínimas inbibitorias "in vitro" lo que da un gran margen de seguridad terapéutica. 


\section{Efectos tóxicos}

Su tolerancia en niños es óptima y la intolerancia a las dosis habituales ( $10 \mathrm{mgr}$.) es muy rara. Cuando se usan dosis altas (20 a $30 \mathrm{mg}$.) pueden aparecer manifestaciones neurológicas: Polineuritis periféricas con sensaciones parestésicas y de quemadura: Irritabílidad, insomnio. Se deben a un efecto competitivo con la Piridoxina (Vitamina B 6) y se observan urticariales o acné, pelagra y alteraciones transitorias de la memoria. Presentación tableta de 50 y $100 \mathrm{mgr}$.

\section{Estreptomicina (SM)}

Antibiótico de alta efectividad, sólo 10 veces menos que la Isoniazida. Sólo se absorbe por vía parenteral (intramuscular), difunde en todo el organismo, excepto en el líquido céfalo raquídeo, en el cual penetra en forma limitada, lentamente. Cuando hay meningitis por aumento de la permeabilidad hay mayor difusión alcanzándose a un 30 a $50 \%$ de la concentración plasmática. Se elimina por la orina.

Se usa preferentemente el Sulfato de Estreptomicina y se ha abandonado la Dihidro-estreptomicina debjdo a su mayor toxiciđad acústica (rama coclear).

Dosis: 20 a $30 \mathrm{mgr}$. por $\mathrm{kg}$. de peso, diario, en dosis única, con un máximo de $750 \mathrm{mgr}$. Se usa la vía intramuscular, la intratecal está abandonada por inútil y peligrosa.

La dosis diaria no debe prolongarse más de 2 meses y se debe continuar según esquema dos veces por semana (junto con HIN) siendo su eficacia igual a la administración diaria.

\section{Efectos tóxicos.}

Su acción sobre la rama vestibular del VIII par (acústico) produce vértigo, mareos y puede llegar a la sordera si no se suspende la droga.

Las reacciones de sensibilidad se manifiestan por parestesias alrededor de la boca y rubicundez de la cara momentos después de la inyección. Exantemas leves. La anafilaxia severa, linfadenopatías $\mathrm{y}$ discrasia sanguíneas son poco frecuentes.

Las personas que manipulan estreptomicina pueden presentar dermatitis o irritación de los párpados (Blefaritis).

Presentación: Frasco ampolla de 1 gramo, liofilizado, para disolver en agua destilada.

\section{Acido paraámino salicílico ( $P A S)$}

Droga sintética poco soluble, de poco efecto bacteriostático útil como acompañante del HIN para prevenir la aparición de resistencia, y por competir con ella en la acetilación retarda su inactivación.
Difunde muy mal al L. C. R. razón por la cual no debe usarse en la meningitis.

La forma más usada es la sal sódica por su mejor tolerancia. Dosis: Se usa 200 a 250 mgr. por $\mathrm{kg}$. de peso al día en lo posible en una sola toma por vía oral.

\section{Efectos tóxicos.}

Intolerancia digestiva y reacciones de hipersensibilidad. Intolerancia: náuseas, vómitos, anorexia, acidez, dolor abdominal. Se logra vencer esta intolerancia con antiácidos y un buen apoyo psíquico de persuasión en sus ventajas.

Alergias, erupciones cutáneas y fiebre son síntomas que obligan a suspender el Pas; puede aparecer una hepatitis grave. Rara vez se presenta una hipokalemia, hiperplasia parotídea y bocio; reacción ganglionar parecida a la Mononucleosis. Presentación: tabletas de $500 \mathrm{mgr}$.

Se altera, produciéndose sustancias irritantes y tóxicas si se exponen a la luz y al calor. Es fácil reconocerla por su cambio de coloración. En estos casos la droga alterada debe desecharse.

\section{Thiodcetazona (TB)}

Eficacia discreta, ha reemplazado al PAS como acompañante de la Isonjazida en algunos esquemas ambulatorios de países subdesatrollados, por su bajo costo y buena aceptabilidad. Sin embargo su toxicidad expresada en dermatitis severas y un bajo porcentaje de anemias aplásticas ha limitado su introducción en gran escala.

Su uso debe ser diario y al parecer no actúa intermitente. Dosis: no son bien conocidas en el niño.

Presentación: En Chile existe un preparado comercial llamado Tiviene: tabletas de $150 \mathrm{mgr}$. de HIN y $75 \mathrm{mgr}$. de Tb cada una. Empíricamente se calcula $10 \mathrm{mgr}$. por $\mathrm{kg}$. de peso de HIN al dia y se da como Tiviene en la proporción de Thiacetazona que corresponda.

\section{Ethionamida (1314) y Prothionamida (1321)}

La Ethionamida es una podexosa droga antituberculosa, de costo elevado y cuya utilidad está significativamente limitada por sus desagradables cfectos colaterales.

Por vía oral su absorción es relativamente Ienta y los niveles tisulares y séricos son prácticamente iguales; atraviesa libremente la barrera hematoencefálica.

Dosis y administración: 15 a $20 \mathrm{mgr}$. por $\mathrm{kg}$. de peso al día, de preferencia en una sola toma. Se ha demostrado que es eficaz asociada al HIN dos veces por semana (lo que desgraciadamente no reduce mucho sus efectos secundarios). 
Efectos tixicos.

Los principales efectos tóxicos son gastrointestinales: vómitos, náuseas, anorexia, pirosis $y$ diarreas. Es frecuente la pérdida de peso en las primeras semanas de tratamiento. Muchos pacientes relatan un gusto desagradable en la boca y eructos sulfurados, síntomas extremadamente difíciles de combatir.

Más raramente se ha comunicado hépato-toxicidad. ginecomastía, artralgias, neuropatía periférica, impotencia, acné, fotodermitis y alopecíi. La Ethonamida es terarogénica en algunos animales de experimentación por lo que debe evitarse su uso durante el embarazo.

La Prothionamida sería de eficacia parecida y algo mejor tolerada.

Presentación: Comprimidos de $250 \mathrm{mgr}$.

\section{Cicloserina (CS)}

Es un antibiótico débil de costo elcvado y de toxicidad relativamente importante.

Dosis y administración: Por vía oral y en iguales dosis que la Ethionamida: 15 - $20 \mathrm{mgr}$. por $\mathrm{kg}$. de peso. No debe emplearse intermitentemente.

\section{Efectos tóxicos.}

Son importantes, fundamentalmente neurológicos. En algunos pacientes se ha observado convulsiones localizadas o generalizadas. Alteracione: psicóticas: excitación, confusión, agresividad o depresión de variada severidad. Es corriente observar síntomas leves como sensación de adormecimiento, pérdida de memoria y pequeños cambios de carácter. Estos sintomas a veces desaparccen con sedantes, pero no pocas veces es necesario suspender la droga. El riesgo más serio que hay que prevenir es el suicidio en pacientes sometidos a tratamientos prolongados con Cicloserina, para lo cual es muy importante la pesquisa de los estados incipientes de depresión.

Presentación: cápsulas de $250 \mathrm{mgr}$.

\section{Pirazinamida (PZ)}

Es una droga potente, de costo elevado y de toxicidad moderada, pero potencialmente peligrosa. Se observa rápidamente a nivel intestinal y se elimina fundamentalmente por la orina.

Dosis y administración: 35 - 40 mgr. por kg. de peso al día por vía oral en una sola toma, con una dosis máxima de $3 \mathrm{~g}$. diarios. Hay evidencias clínicas que sería más efectiva intermitentemente que diariamente (aumentando la dosis unitaria de modo que dosis semanal sea la misma).
Efectos tóxicos.

El más importante es la hepatitis que puede ocurrir hasta en el $6 \%$ de los casos que reciben $40 \mathrm{mgr}$. por $\mathrm{kg}$. de peso durante 24 semanas. La hépato-toxicidad se presenta en relación dirceta con la dosis y puede ser fatal; hay algunas evidencias que sugieren que puede deberse a una reacción de hipersensibilidad. La Pirazinamida debe emplearse en centros en que se pueden hacer estudios seriados de transaminasas y suspenderla cn cuanto aparezca un aumento significativo de sus valores (cifras repetidas sobre 100 unidades). La rápida normalización es la regla, después de la suspensión de la droga.

Más raramente puede observarse fotosensibilidad, prcduciéndose una coloración caférojiza en las zonas expuestas de la cara y manos. Por último puede determinar rash cutáneo y cierto grado de fotofobia.

Presentación: tabletas de $500 \mathrm{mgr}$.

\section{Ethambutol (EMB)}

Es una poderosa droga antituberculosa, de costo elevado y de toxicidad baja. No tiene resistencia cruzada con otros agentes antituberculosos.

Es activo por vía oral con rápida y completa absorción; ste elimina preferentemente por la orina.

Dosis y administración: Se recomienda la dosis de $25 \mathrm{mgr} . / \mathrm{kg}$. por dia hasta el término del tratamiento, en una sola toma al día. Hay evidencias que sería más efectiva administrada en dosis unitarias más elevadas, en forma intermitente.

La toxicidad más importante se refiere a la neuritis tóxica retrobulbar del nervio óptico que está en rclación directa con la dosis usada y que obliga a controles visuales seriados antes y durante el tratamiento. Las manifestaciones tóxicas comicnzan con visión borrosa de instalación gradual y alteración de la visión de colores con contusión del verde con el rojo; puede haber escotonas centrales y disninución del campo visual periférico. En casi todos los casos comunicados el daño ha sido completamente reversible, después de la suspensión de la droga,

No se ha descrito toxicidad óptica con las dosis recomendadas anteriormente.

Se ha descrito neuritis periférica como manifestación secundaria muy rara. No se ba observado ningún otro efecto tóxico y la tolerancia es perfecta.

Presentación: tabletas de 200 y $400 \mathrm{mgr}$.

\section{Kanamicina (KM)}

Eficacia mediana, costo muy elevado, toxicidad moderada. En su forma de sulfato es muy soluble y estable. No se absorbe prácticamente por vía oral. Administrada intramuscularmente 
alcanza rápidamente niveles altos eliminándose por la orina en altas concentraciones.

Dosis y administración: Por vía intramuscular, en dosis de 10 - $15 \mathrm{mgr}$. por $\mathrm{kg}$. de peso al día con un máximo de $750 \mathrm{mgr}$. Empleada intermitentemente, para evitar su toxicidad, sería menos efjcaz, por lo menos a las dosis habituales.

\section{Efectos tóxicos.}

Es tóxica sobre el VIII par produciendo tanto alteraciones vestibulares como cocleares (sordera). Es, además nefrotóxica. Generalmente determina daño permanente, por lo que esta droga sólo puede emplearse en casos especiales y por tiempo no muy prolongado, aunque en personas jóvenes generalmente puede administrarse por unos pocos meses sin problemas.

Otras manifestaciones menos frecuentes: parestesias, inquietud, dolor $\mathrm{y}$ nódulos persistentes en el sitio de la inyección; rash cutáneo y otras manifestaciones alérgicas.

Presentación: Frasco-ampolla de $0,5 \mathrm{gr}$.

\section{Viomicina (VM)}

Eficacia parecida a la Kanamicina, pero mucho más tóxica por lo cual su uso es extremadamente restringido.

Dosis y administración: Frasco ampolla de 1 g. para inyección I. M. 20 a 30 mgr. kg. día por 5 días a la semana.

\section{Efectos tóxicos.}

Daño sobre el VIII par, daño renal, alteraciones electrolíticas con hipocalcemia e hipokalemia, retención de agua con edema.

\section{Capreomicina (CM).}

Eficacia similar a Kanamicina y Viomicina, pero con una toxicidad que sería aún menor que la de la Estreptomicina.

Dosis y administración: 20 a $30 \mathrm{mgr}$. kg. diario sin sobrepasar $750 \mathrm{mg}$. intramuscular, que se puede mantener por muchos meses, especialmente en gente joven. No se conoce su poteneialidad para uso intermitente.

\section{Efectos tóxicos.}

Daño sobre VIII y sobre el riñón.

Presentación: Frasco ampolla de $1 \mathrm{~g}$.

Aunque la experiencia con esta droga es escasa, se piensa que podría reemplazar a la Kanamicina debido a su menor toxicidad $y$, eventualmente, a un menor precio.

\section{Rifampicina (RMP).}

Es un compuesto semi sintético derivado de la Rifamicina. Es una droga muy potente y de muy baja toxicidad. Parece ser un medicamento prometedor, bactericida a las dosis usuales, con un margen de seguridad que hace que los niveles séricos sean alrededor de 100 veces superiores a la dosis mínima inhibitoria. Se piensa que probablemente en el futuro pueda incorporarse al grupo de las drogas de primera línea y ubicarse a la diestra de la Isoniazida. Son ya numerosos los investigadores que la consideran más potente que ésta.

Dosis y administración: Alrededor de $10 \mathrm{mgr}$. por $\mathrm{kg}$. diarios, en ayunas, condición en la que su absoción es máxima. Trabajos recientes parecen demostrar que, aumentando las dosis unitarias, sería más efectiva administrada intermitentemente, aún con dosis semanales totales inferiores a las que se alcanzan al emplear diariamente. Aparentemente el efecto bactericida de esta droga a dosis adecuadas es extraordinario.

\section{Efectos tóxicos.}

No se conocen bien. Se recomienda no usarla en embarazadas porque se ha observado cierta acción teratogénica en animales de experimentación. Por el momento, aparece como poco tóxica. Una eventual toxicidad hepática está en discusión y en todo caso sería muy infrecuente. Empleada intermitentemente produce una hipersensibilidad especial con piaquetopenia y sangramiento.

Presentación: Cápsulas de 150 mgr. Jarabe de $100 \mathrm{mgr}$. por $5 \mathrm{ml}$. 